\title{
Reconstructive procedures in maxillofacial oncosurgery
}

\author{
Richard Pink ${ }^{\mathrm{a}}$, Martin Molitor ${ }^{\mathrm{b}}$, Peter Tvrdy ${ }^{\mathrm{a}}$, Petr Michla ${ }^{\mathrm{a}}$, Jindrich Pazdera ${ }^{\mathrm{a}}$, Vitezslav Zborila, Bohumil Zalesak ${ }^{\mathrm{b}}$
}

\begin{abstract}
Objective. Oropharyngeal cancers are a biologically heterogenous group of tumors with diverse risk factors including tobacco, alcohol, HPV, inherited disorders, the acquired immunodeficiency of Karposi's Sarcoma and non Hodgkin's lymphoma. In the Czech Republic, oropharyngeal cancers represent around 2\% of all cancers. The treatment of these tumors is long and complex. Reconstructive procedures in maxillofacial oncosurgery demand good interdisciplinary collaboration and great professional preparedness of the surgical and nursing team. Patient age and stage of disease, including the presence of metastases are of key importance. A prerequisite for the success of surgical treatment is removal of the tumor with a sufficient safety margin. Reconstructive procedures then follow.
\end{abstract}

Aim. To highlight the importance of radical tumor resection and describe reconstruction of the defect in a group of our patients.

Methods and Results. From 2008 to 2013, 23 patients with oropharyngeal carcinoma underwent radical surgical removal of tumor, followed by reconstruction of postoperative defects using distant and free flaps. The histopathology showed predominantly squamous cell carcinomas and one of Merkel cell carcinoma. 16 patients had malignant disease detected in III-IV.

In only 7 cases was treatment initiated in the first and second stages of the disease. In these patients, the tumors were removed with a safety margin of healthy tissue and in none, did the basic cancer recur. The postoperative course in terms of flap engraftment and overall condition of the patient was uneventful. All of these patients still enjoy a good life quality with a current mean survival in range 5-76 months. Radical surgical removal of a malignant tumor in the early stages of the disease is associated with fewer postoperative complications and longer survival.

Conclusion. To avoid the risk of local and/or systemic postoperative complications, appropriate patient selection is important. Overall, the traditional, classic reconstructive procedures with the use of prostheses, in many cases is still the best option in our experience.

Key words: reconstruction of defects, free flaps

Received: April 11, 2014; Accepted: October 15, 2014; Available online: November 7, 2014 http://dx.doi.org/10.5507/bp.2014.055

${ }^{a}$ Department of Oral and Maxillofacial Surgery, University Hospital Olomouc, Czech Republic ${ }^{b}$ Department of Plastic and Aesthetic Surgery, University Hospital Olomouc, Czech Republic Corresponding author: Peter Tvrdy, e-mail: Peter.Tvrdy@fnol.cz

\section{INTRODUCTION}

Oropharyngeal cancers are among the 10 most frequent cancers in the world with increases every year of around 500,000 new cases. Only about one third of patients survive 5 years following diagnosis. The percentage of these tumors in the Czech Republic is around 2\% (3\% in the USA, in the countries of Southeast Asia from 35 to $40 \%$ ). Rational treatment of oropharyngeal cancers is complex and long. Selection of optimal treatment modalities depend on the biological nature of the tumor, its size and location. From a therapeutic viewpoint, patient age, overall health and stage of malignancy are of paramount importance.

Currently, surgical treatment of malignant tumors of the head and neck still dominates. A prerequisite is to remove the whole tumor with a sufficient safety mar$\operatorname{gin}^{1,2}$. Reconstruction surgical procedures in oncosurgery include local flap, reconstruction of soft tissue defects using free dermo-epidermal grafts and complex microsurgical procedures. Small tumors usually do not require reconstruction of defects. In advanced cancer, however, simple reconstruction is inadequate and we use free flaps. The principle is to take tissue from a remote location and transfer it to the defective site after careful vascular anastomosis. The immediate postoperative period is of great importance requiring continuous monitoring of blood supply and patency of graft, using direct and indirect techniques. With the lapse of time after surgery, the patient usually requires additional surgical treatment (remodeling) of transferred flap.

A total of 23 reconstructive procedures using free flaps (Table 1) were carried out at the Department of Oral and Maxillofacial Surgery in the years 2008 - 2013 in collaboration with the Department of Plastic and Aesthetic Surgery, both of the University Hospital Olomouc. The sample included 18 men and 5 women, in the majority of cases smokers with a positive attitude towards alcohol. 22 patients were treated for squamous cell carcinoma and one patient was treated for Merkel cell carcinoma.

Selecting the reconstruction proces depends on the general health of the patient and the stage of the malignancy. For reconstruction we used free osteomyocutaneous, myocutaneous flaps or remote flaps (Fig. 1) For 
reconstruction of the lower jaw and surrounding soft tissues we mostly use bone grafts from the fibula, which, compared with the iliac crest have a lower tendency to resorption (Fig. 2-4).

After surgery, we monitored the patency of the grafts, mainly by direct methods (visualisation, palpation) or by localized cutaneous island in the mouth. The indirect method we used was Doppler flowmetry .

For the free flaps for reconstruction of the defects, we used pectoral flaps. In two patients, this flap reconstructed the face and in one case, defects after subtotal resection of the base of the tongue and oral cavity.

\section{RESULTS}

Sixteen of patients had malignant disease detected in III-IV stage (Table 2). In only 7 cases (Table 1 , patients No. 2, 5, 10, 18, 19, 20, 21), was treatment initiated in the first and second stages of the disease. In all these patients, the tumors were removed with a safety margin of healthy tissue and in none, did the basic cancer recur. The postoperative course in terms of flap engraftment and overall condition of the patient was uneventful. All of these patients still enjoy a good life quality with a current mean survival in range 5 - 76 months. Sixteen patients started treatment in stages III. - IV. of malignancy. Ten (Table 1, patients No. 1, 6, 7, 9, 11, 12, 13, 14, 15, 22) died of locoregional recurrence with a median survival of 19 months. Except for one patient treated for Merkel cell carcinoma, all these patients had positive resection margins, and local and systemic complications of surgical treatment were common (Table 2). One patient (No. 12) died on the second postoperative day of pulmonary embolism. In patient No. 6, the free fibula flap failed to engraft and the defect had to be subsequently reconstructed using an $\mathrm{m}$. latissimus dorsi flap. The mandibular defect in patient (No. 7) was reconstructed after osteomyelitis of the mandible with chin extraoral fistula. The osteomyelitis was treated with systemic and local antibiotics (Dalacin $600 \mathrm{mg}$ iv, Garamycin ) and skin defect in the submental area after excision of the oral cutaneus fistula was reconstructed using free flap - musculus rectus abdominis. In one case (No. 8) there was fracture of titanium osteosynthetic plate in the angle of the mandible and subsequent osteomyelitis of the fibula. This complication we managed by removal of the plate, fibula and mandibular resection margins and replaced it with more rigid material. The patient treated for Merkel cell carcinoma (No. 14) died two years after surgery. The cause of death was generalised primary oncological disease (lymphoma).

\section{DISCUSSION}

The technique of microvascular free flap was first used by Seidenberg in 1959 for reconstruction of the esophagus (jejunal flap) $\left(\right.$ ref. $\left.^{3}\right)$. Later the Australian team led by Taylor in 1975 succeeded in reconstruction of bone defect using free fibula. Reconstruction of the lower jaw using the fibula was first done by Hidalgo $0^{4,5}$. Then in the $1980 \mathrm{~s}$ began a period of rapid development in microvascular reconstructive surgery

Table 1. Summary of patients after reconstruction with free and distant flaps.

\begin{tabular}{|c|c|c|c|c|c|c|}
\hline Patient & Gender & pTNM & $\begin{array}{l}\text { Tumor } \\
\text { type }\end{array}$ & Localisation & $\begin{array}{l}\text { Primary/secondary } \\
\text { surgical procedure }\end{array}$ & Type of flap \\
\hline 1. & male & pT3N1Mx & SCC & Base of mouth & primary & Iliac crest flap \\
\hline 2. & female & pT2N0Mx & SCC & Madibule alveolus & Primary & Free fibula flap \\
\hline 3. & female & pT4N2cMx & SCC & Base of mouth + alveolus & Primary & Free fibula flap \\
\hline 4. & male & pT4N2bMx & SCC & Alveolus & Secondary/recidivism & Anterolateral flap \\
\hline 5. & male & pT2N0Mx & SCC & Alveolus & Secondary/recidivism & Anterolateral flap \\
\hline 6. & male & pT3N0Mx & SCC & radix of tongue & Secondary & Free fibula+latissimus dorsi flap \\
\hline 7. & male & pT4N0Mx & SCC & Base of mouth & Primary & Free fibula/rectus abdomis flap \\
\hline 8. & male & pT4N1Mx & $\mathrm{SCC}$ & Base of mouth & Primary & Free fibula flap \\
\hline 9. & male & pT4N1Mx & SCC & Mandible alveolus & Primary & Free fibula flap \\
\hline 10. & female & pT1N0Mx & SCC & Mandible alveolus & Secondary & Free fibula/latissimus dorsi flap \\
\hline 11. & male & pT3N2bMx & SCC & cheek & Secondary & Anterolateral flap \\
\hline 12. & male & pT4N2bMx & $\mathrm{SCC}$ & Tonsils + radix of tongue & Primary & latissimus dorsi flap \\
\hline 13. & male & pT3N2bMx & SCC & Alveolus & Secondary & free fibula flap \\
\hline 14. & female & pT3N3Mx & $\mathrm{MCC}$ & cheek & Primary & latissimus dorsi flap \\
\hline 15. & female & pT4N2Mx & $\mathrm{SCC}$ & Tuber maxilla & Primary & latissimus dorsi flap \\
\hline 16. & male & pT4N3Mx & $\mathrm{SCC}$ & Maxillary sinus & Primary & latissimus dorsi flap \\
\hline 17. & male & pT4N0Mx & SCC & Upper lip & Secondary & Radial forearm flap \\
\hline 18. & male & pT2N0Mx & SCC & cheek & Primary & Rectus abdominis flap \\
\hline 19. & male & pT2N0Mx & SCC & cheek & Primary & Latissimus dorsi flap \\
\hline 20. & male & pT1N0Mx & SCC & Floor of mouth & Primary & Pectoralis major flap \\
\hline 21. & male & pT2N1Mx & SCC & cheek & Primary & Pectoralis major flap \\
\hline 22. & male & pT3N2bMx & SCC & cheek & Primary & Pectoralis major flap \\
\hline 23. & male & pT3N1Mx & SCC & Floor of tongue & Primary & Pectoralis major flap \\
\hline
\end{tabular}

SCC - Squamous cell carcinoma, MCC - Merkel cell carcinoma 
Table 2. Results (recurence, positivity of the margins, complications) of the patients after reconstruction.

\begin{tabular}{|c|c|c|c|c|}
\hline Patient & Margins & Recurrence & Complications & Survival/death \\
\hline 1 & - & Yes in 9 months & & Death after 12 months \\
\hline 2 & - & Yes in 60 months & & Alive at 76 months \\
\hline 3 & - & No & & Alive at 82 months \\
\hline 4 & + & No & & Alive at 19 months \\
\hline 5 & - & No & & Alive at months \\
\hline 6 & + & Yes in 9 months & Total failer & Died after 42 months \\
\hline 7 & + & Yes in 29 months & Osteoradionecrosis of fibula & Died after 36 months \\
\hline 8 & - & No & Osteoradionecrosis of fibula & Alive at 43 months \\
\hline 9 & + & Yes in 29 months & Osteoradionecrosis of fibula & Died after 40 months \\
\hline 10 & - & No & & Alive at 49 months \\
\hline 11 & + & Yes in 4 months & & Died after 5 months \\
\hline 12 & & & Embolism & Died second day after operation \\
\hline 13 & + & Yes in 5 months & & Died after 7 months \\
\hline 14 & - & No & & Died after 20 months \\
\hline 15 & + & Yes in 16 months & & Died after 20 months \\
\hline 16 & - & No & & Alive at 23 months \\
\hline 17 & - & No & & Alive at 39 months \\
\hline 18 & - & No & & Alive at 16 months \\
\hline 19 & - & No & & Alive at 13 months \\
\hline 20 & - & No & & Alive at 5 months \\
\hline 21 & - & No & & Alive at 5 months \\
\hline 22 & + & Yes in 3 months & & Died after 4 months \\
\hline 23 & - & No & & Alive at 3 months \\
\hline
\end{tabular}

+ positive margin, - negative margin

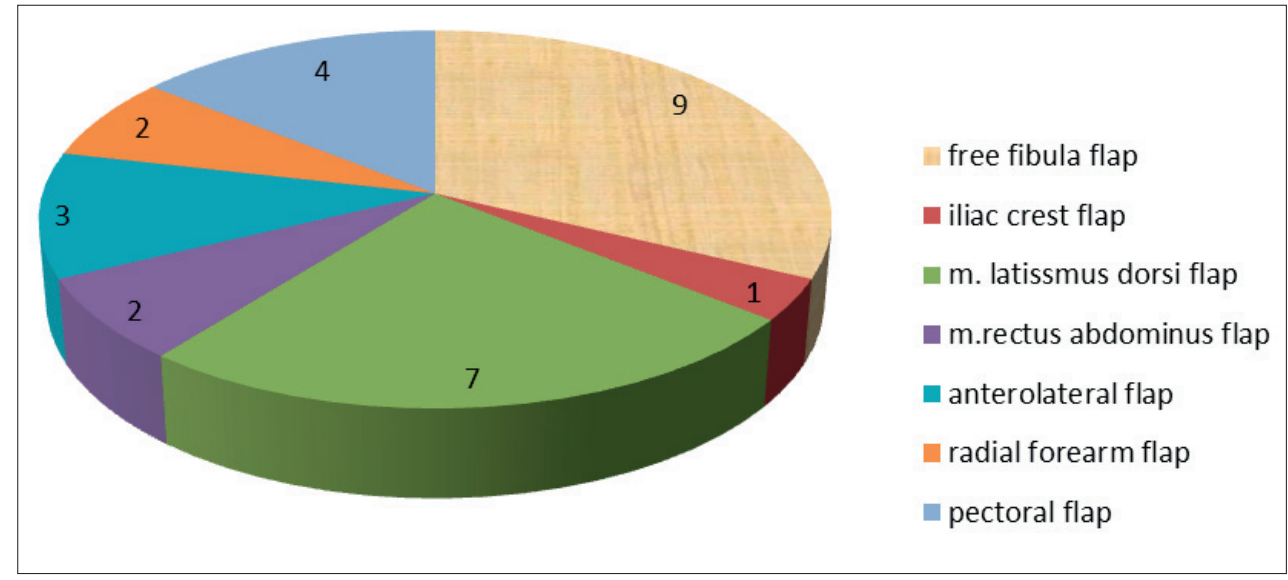

Fig. 1. Distribution of flaps used for reconstruction.

Defects in the head and neck can, according to anatomical location and reconstructive technique, be divided into six: intraoral, mandibular, middle face, mouth and tongue floor defects and scalp defects ${ }^{6}$.

Intraoral defects include tongue, base of the oral cavity, face, hypopharynx, larynx and cervical esophagus. Experience shows that defects of the tongue of less than $50 \%$, can be reconstructed primarily by simple suture or sculptured local flap ${ }^{7}$. For large defects of the tongue (50$70 \%$ ) reconstruction using free flap is a virtual necessity but questionable in the case of large tumors involving subtotal to total glossectomy. It is an extensive, mutilating performance to remove the tumor and as the literature attests to, total rehabilitation of lobar structure of the tongue is very difficult, if not impossible ${ }^{8,9}$. The results of reconstruction of the tongue (swallowing, phonation) using free flap depend on the amount of remaining healthy tissue to ensure its mobility ${ }^{10}$. In our department, we encounter tumors in the early stages (T1 favorable sites) requiring mostly extirpation with primary suture and possibly local flap reconstruction. After surgical removal of large tumors, for satisfactory functional rehabilitation, reconstruction of the defect is usually essential. For large tumors of the tongue (T4) radical surgical therapy is often the only treatment option. In the oral cavity the flap should be soft and malleable, and therefore frequently used is the Chinese forearm flap, first done in practice in the early $1980 \mathrm{~s}^{11}$. The advantage of this flap is long pedicle (a. et v. radialis) and accompanying superficial venous blood vessels which can be used for additional ve- 


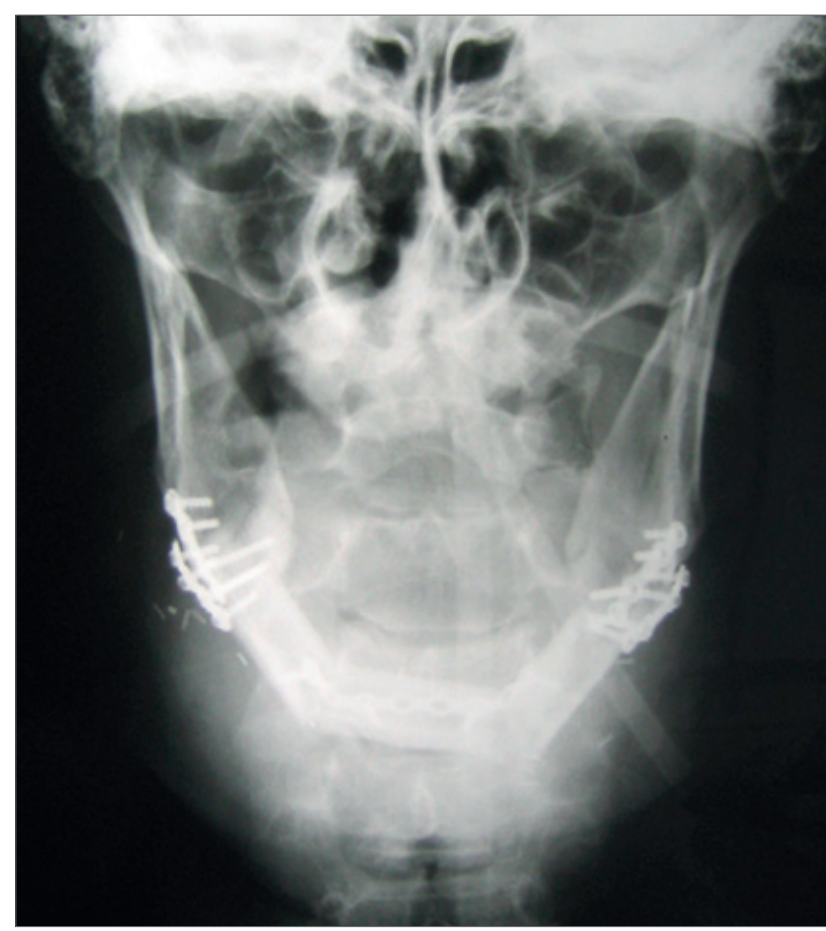

Fig. 2. Free fibula after fixation in defect.

nous anastomosis and prevent venostasis. Along with the flap, we can also remove the palmaris longus tendon or bone part of the spindle, which can be used to reconstruct the lip muscle or for jaw bone defects. This option was employed in one of our patients after partial resection of the upper lip and premaxilla with large cell carcinoma of the upper lip. In our patients with intraoral tumors and depending on the size of the defect, we use both latissimus dorsi muscle and rectus abdominis and forearm flap. For reconstruction of the tongue after subtotal glossectomy in one case we used the pectoral flap with very good functional and aesthetic results.

Defects of the hypopharynx, larynx and cervical esophagus can be reconstructed for example using free jejunum, colon or anterolateral thigh flap.

For reconstruction of mandibular defects most used is vascularized bone. Reconstruction is necessary especially in postoperative defects localized in the frontal parts of the jaw, where we have to avoid instability of the tongue, with the subsequent risk of asphyxia ${ }^{8,12}$. Osteomyocutaneous flap which includes free fibula can be used to reconstruct the body of the mandible, the alveolar mucosa and lower lip, oral cavity and the base of the tongue. In the lateral section of the lower jaw we have more options. In young individuals we try to reconstruct the defects usually using vascularised bone (free fibula, iliac crest) or reconstruction plates ${ }^{13}$. In elderly patients with uncertain prognosis the mandibular defects are left wihout reconstruction and soft tissue is replaced using local flap.

Opinions on the reconstruction of defects of the upper jaw and middle face vary. Devin et al. divide the defects of the upper jaw according to extent into three categories ${ }^{14}$.

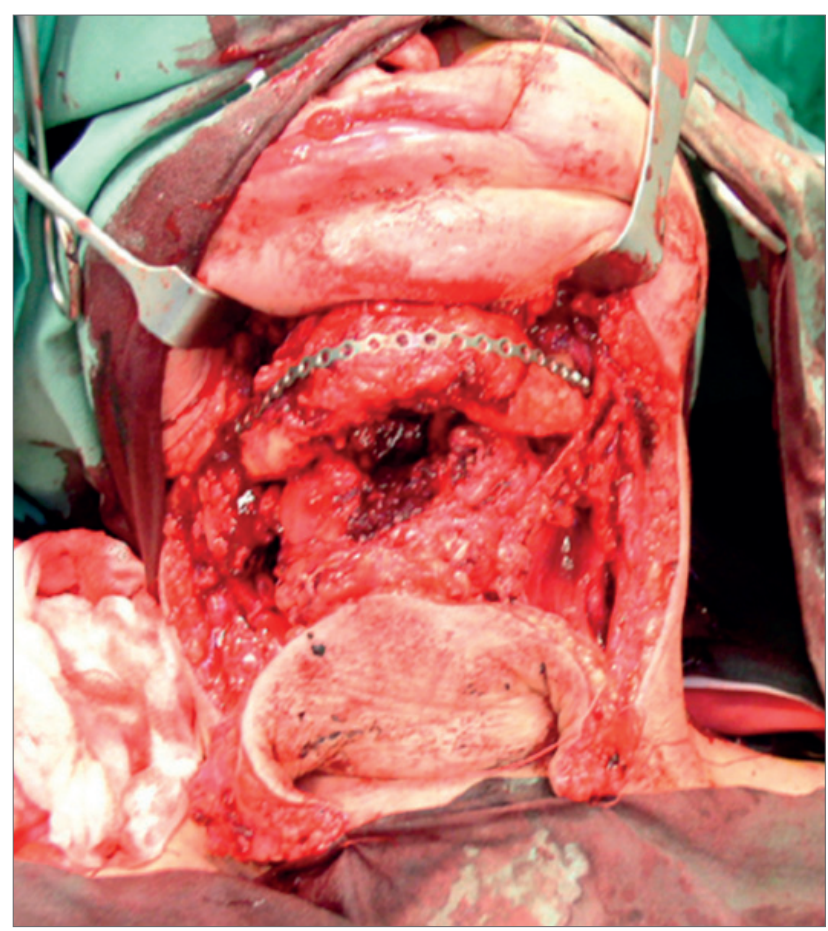

Fig. 3. Frontal image of skull after reconstructive surgery.

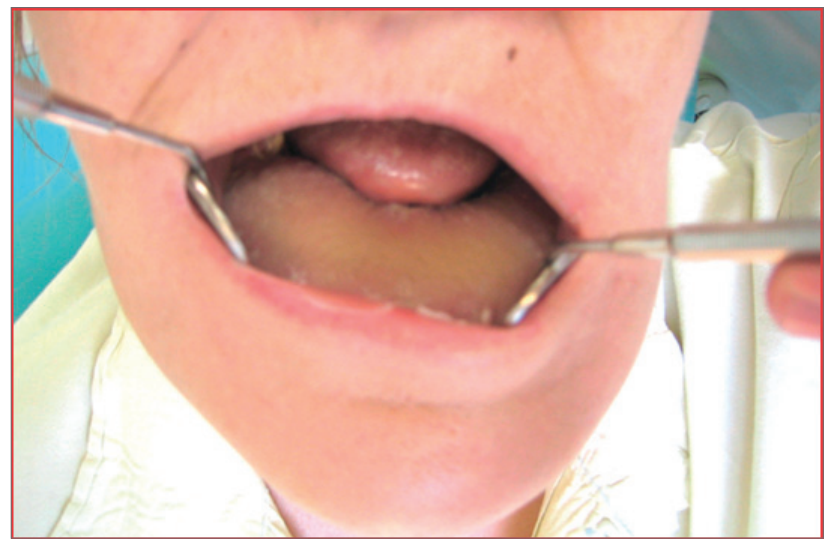

Fig. 4. Results after reconstruction of lower jaw and defect of soft tissue in floor of mouth.

Small defects I. and II. category can most elegantly be solved by prosthesis and dentures. In some patients, however, prosthetic rehabilitation is poorly tolerated and may require surgical alternatives to local or free flap. In some cases (e.g. defects of the hard palate with the transition to the alveoli ) the lobar sculpture may complicate visual inspection of the surgical field in the oncological department and be an obstacle to satisfactory future denture retention. For large defects of III. category where more than half of the upper jaw is missing, recommended is reconstruction of the defect using free osteomyocutaneous flap. In this way, it is possible to reconstruct the alveolar process and create the conditions for dental implants. 


\section{CONCLUSIONS}

Challenging reconstructive procedures in orofacial oncosurgery require very good interdisciplinary cooperation, high clinical expertise of the surgical team composed of maxillofacial and plastic surgeons, dedication, and hardworking nurses. Very important is the responsibility of patient selection, awareness and motivation for surgery. It is also important to realize that free flaps may not always be the only possible solution the use of conventional dentures or prosthetic devices may be in some cases easier and much more efficient.

Author contributions: RP, JP: manuscrip writing; PM: data collection, data nalysis; MM, BZ: study design; PT, VZ: final approval.

Conflict of interest statement: None declared.

\section{REFERENCES}

1. Looser KG, Shah JP, Strong EW. The significance of "positive" margins in surgically resected epidermoid carcinomas. Head Neck Surg 1978;1:107-11.

2. Scholl P, Byers RM, Batsakis JG. Microscopic cut-through of cancer in the surgical treatment of squamous carcinoma of the tongue. Prognostic and therapeutic implications. Am J Surg 1886;152:35460.
3. Seidenberg B, Rosenak SS, Hurwitt ES, Som ML. Immediate reconstruction of the cervical esophagus by a revascularized isolated jejunal segment. Ann Surg 1959;149:162-71.

4. Taylor IG, Miller GDH, Ham FJ. The Free Vascularized Bone Graft. Plastic and Reconstructive Surgery 1975;55(5):533-44.

5. Hidalgo DA. Fibula Free Flap: A New Method of Mandible Reconstruction. Plastic and Reconstructive Surgery 1989;84(1):71-9.

6. Thorwarth M, Eulzer C, Bader R, Wolf C, Schmidt M, Schultze-Mosgau $S$. Free flap transfer in cranio-maxillofacial surgery: a review of the current data. Oral Maxillofac Surg 2008;12(3):113-24.

7. McConnel FM, Pauloski BR, Logemann JA, Rademaker AW, Colangelo $L$, Shedd D. Functional results of primary closure vs flaps in oropharyngeal reconstruction: a prospective study of speech and swallowing. Arch Otolaryngol Head Neck Surg 1998;124:625-30.

8. Urken ML, Moscoso JF, Lawson W, Biller HF. A systematic approach to functional reconstruction of the oral cavity following partial and total glossectomy. Arch Otolaryngol Head Neck Surg 1994;120:589601.

9. Khariwala SS, Vivek PP, Lorenz RR, Esclamado RM, Wood B, Strome $M$. Swallowing outcomes after microvascular head and neck reconstruction: a prospective review of 191 cases. Laryngoscope 2007;117:1359-63.

10. Smith RB, Sniezek JC, Weed DT, Wax MK. Utilization of free tissue transfer in head and neck surgery. Otolaryngol Head Neck Surg 2007;137:182-91.

11. Yang G, Chen B, Gao Y, Liu X, Li J, Jiang S, He S. Forearm free skin flap transplantation. Natl Med J China 1981;61:139-41.

12. Rosenthal E, Couch M, Farwell DG, Wax MK. Current concepts in microvascular reconstruction. Otolaryngol Head Neck Surg 2007;136:519-24.

13. Boyd JB, Gullane PJ, Rotstein LE, Brown DH, Irish JC. Classification of mandibular defects. Plast Reconstr Surg 1993;92:1266-75.

14. Okay D, Genden E, Buchbinder D, Urken M. The journal of prosthetic dentistry. Prosthodontic guidelines for surgical reconstruction of the maxilla, 2001;86:352-63. 